\title{
Quantitative comparison of Pleistocene and Recent coral reef habitats in the northern Red Sea (El Quseir, Egypt)
}

\author{
Stella Jane Alexandroff ${ }^{1,2} \cdot$ Martin Zuschin $^{1} \cdot$ Andreas Kroh $^{3}$
}

Received: 7 September 2015 / Accepted: 17 March 2016 / Published online: 26 March 2016

(C) The Author(s) 2016. This article is published with open access at Springerlink.com

\begin{abstract}
Fossil reefs have the potential to provide important data for studies of climate and environmental change. This is particularly true for Pleistocene-Holocene coral reefs, which predominantly consist of communities undisturbed by anthropogenic impact and therefore provide a baseline for evaluating the status of modern reefs. We used photo transects and point-counting to quantitatively compare two Pleistocene reef terraces of two Pleistocene sites, tentatively assigned to marine isotope stage $5 \mathrm{e}$, with habitats (reef flat, reef edge, reef slope at 5- and 10-m water depth) of a modern reef near El Quseir, Egypt. The modern reef exhibits a clear trend of increasing taxonomic richness and diversity from the reef flat towards the reef slope at 10-m water depth. The most abundant genera are Pocillopora, Acropora, Millepora, and massive Porites, but strong differences between individual habitats were evident. The most abundant genera in the fossil reefs are massive Porites and Dipsastraea. With regard to quantitative composition, all modern reef habitats differed significantly from each other as well as from the fossil reefs. The fossil reef composition is most similar to the modern reef slope habitat at $10-\mathrm{m}$ water depth. There are two conflicting hypotheses
\end{abstract}

Electronic supplementary material The online version of this article (doi:10.1007/s10347-016-0468-6) contains supplementary material, which is available to authorized users.

Stella Jane Alexandroff

s.alexandroff@bangor.ac.uk

1 Department of Palaeontology, University of Vienna, Althanstrasse 14, 1090 Vienna, Austria

2 School of Ocean Sciences, Bangor University, Askew Street, Menai Bridge, Wales, UK

3 Naturhistorisches Museum Wien, Burgring 7, 1010 Vienna, Austria on geodynamic processes for this area-these are tectonic uplift and tectonic stability. Considering tectonic stability, the fossil reefs would have to be interpreted as lagoonal patch reefs, for which no modern counterparts exist in the study area. However, in the case of tectonic uplift, we conclude that the fossil reefs studied were once situated at around 10-m water depth.

Keywords Taphonomy · Paleoecology · Invertebrates · Coral composition $\cdot$ Reefs

\section{Introduction}

Coral reefs are geological and biological structures that preserve environmental data over thousands of years. This makes them useful proxies for sea level (Edinger et al. 2007) and climate change (e.g., Lough and Barnes 1997) and enables studying these factors on reef-coral communities in the fossil record (Pandolfi and Greenstein 2007). Comparing fossil with extant reef communities requires methods that can be employed in both settings. Here we present a case study using photo transects and pointcounting of coral coverage and community composition to compare past and present reefs from the Egyptian Red Sea coast. A number of features make the Red Sea region an excellent setting for such an approach: (1) Extensive outcrops of fossil reefs occur parallel to and in close proximity of the modern coastline; (2) these are better preserved than many tropical terraces, and (3) the young age of the lowest reef terrace facilitates direct comparison with modern reef communities.

Pleistocene reef terraces of the Red Sea have been studied since the late 19th century (Walther 1888) and have been investigated over the past few decades with respect 
to sea level changes, microfacies, diagenesis, age, and faunal composition (Veeh and Giegengack 1970; Dullo 1986, 1990; Andres et al. 1988; Hoang and Taviani 1991; El Moursi et al. 1994; Gvirtzman 1994; Bosworth and Taviani 1996; Strasser and Strohmenger 1997; Taviani 1998a, b; Plaziat et al. 2008; Lambeck et al. 2011; Parker et al. 2012; Mewis and Kiessling 2013). To our knowledge, however, no study has quantitatively compared the faunal composition of modern and nearby fossil reefs in an attempt to define the original depositional water depth. This is especially worthwhile for the lowermost terraces of marine isotope stage (MIS) 5e, which show relatively minor diagenetic alteration (Gvirtzman and Friedman 1977; Dullo 1984, 1986). These reefs are the most promising target for a past-modern comparison and for evaluating community stability over geological time scales.

We therefore compare two Pleistocene reef terraces, tentatively assigned to MIS 5e, to the reef flat, reef edge, and reef slope at 5- and 10-m water depth of a modern fringing reef at the Egyptian coast of the Red Sea. An estimation of paleo-depth is a prerequisite for comparative studies because faunal composition of reefs is strongly depth controlled (e.g., Riegl and Velimirov 1994).

This work was designed to test whether the original water depth of Pleistocene reef terraces can be determined from their taxonomic composition. The main objectives were to (1) characterize the modern and fossil reef habitats regarding their taxonomic composition and diversity, to then (2) assess how similar the fossil reef terraces are to the different modern habitats.

\section{Materials and methods}

\section{Study area}

The Recent reef is located at Abu Sauatir (Fig. 1), $12 \mathrm{~km}$ northwest of El Quseir $\left(26^{\circ} 12^{\prime} 25^{\prime \prime} \mathrm{N}, 34^{\circ} 13^{\prime} 13.2^{\prime \prime} \mathrm{E}\right)$. We divided it into four habitats: reef flat, reef edge, reef slope at a depth of $5 \mathrm{~m}$, and reef slope at a depth of $10 \mathrm{~m}$ (Fig. 2). The reef is naturally divided into a northern and a southern part by a wadi mouth.

The fossil reef terraces are located at Abu Dabbab, $97 \mathrm{~km}$ southeast of El Quseir $\left(25^{\circ} 19^{\prime} 56^{\prime \prime} \mathrm{N}, 34^{\circ} 44^{\prime} 36^{\prime \prime} \mathrm{E}\right)$, and at El Mohgar, $13 \mathrm{~km}$ southeast of El Quseir $\left(26^{\circ} 0^{\prime} 12.3^{\prime \prime} \mathrm{N}\right.$, $\left.34^{\circ} 20^{\prime} 7^{\prime \prime} \mathrm{E}\right)$. They are the lowest terraces at these sites and were studied 3-5 $\mathrm{m}$ above present sea level (Fig. 3a). The reef consists of coral framestones, bindstones dominated by coralline red algae or vermetid gastropods, and rud- and grainstones, consisting of coral fragments, mollusks, and echinoderm debris (Fig. 3b-f). Corresponding to ages provided for nearby terraces, the reefs are tentatively assigned to MIS 5e (i.e., the Eemian stage) between 115 and $130 \mathrm{kyr}$ before present (Plaziat et al. 2008).

\section{Field methods}

To evaluate the taxonomic composition of the modern reef habitats, 16 quadrats of $0.25 \mathrm{~m}^{2}$ per habitat were photographed during snorkeling (reef flat and edge) or SCUBA diving (reef slope) along transects in April 2012. The reef edge transects were done at approx. 2-m water depth: the wave energy prohibited sampling at shallower depths in this habitat at any time of day. The starting point of each transect was chosen randomly; from there, photographs were taken at intervals between 0.5 and $2 \mathrm{~m}$ using a $50 \times 50-\mathrm{cm}$ metal frame for scaling. The reef flat was divided into a proximal and a distal transect of eight quadrats, respectively; the reef edge and the reef slope at $10-\mathrm{m}$ depth were divided into northern and southern transects with eight quadrats each.

In the fossil reef, we used line transects similar to those in the Recent reef. At El Mohgar, we took photographs of 23 quadrats every $2 \mathrm{~m}$ along a tape measure. At Abu Dabbab, 16 quadrats were photographed without leaving a gap between the individual frames.

The modern sites were evaluated exclusively by analyzing photographs. For each quadrat, several full-view and detail images were taken. In the fossil reefs, in addition, quadrats were drafted on paper and major constituents identified directly in the field to better distinguish between in situ corals and coral rubble.

Point-counting was used to produce a quantitative dataset of the taxonomic composition. A grid with 100 intersection points was added to the best full-view image for each quadrat, resulting in 1600 data points for each of the four modern reef habitats and the fossil reef at Abu Dabbab, respectively, and in 2300 data points for El Mohgar. Using the detail-view images, the taxon under each intersection was identified and counted. Percentages of the counts were arcsine-root-transformed prior to statistical analysis to gain linear data (Legendre and Legendre 1998). Photo-quadrat (Bohnsack 1979 and references therein) and grid-point intercept sampling (e.g., Pilliod and Arkle 2013) are efficient survey methods, although there might be limitations when sampling rare taxa. The standard error of sample proportion for each taxon in the modern reef habitats (flat, edge, slope $5 \mathrm{~m}$, and slope $10 \mathrm{~m}$ ) and the fossil reef terraces was calculated using the equation $\mathrm{SE}=\sqrt{\frac{p \times(1-p)}{n}}$ and yielded values between 0.3 and $1.2 \%$. It is worth noting, however, that the size of a coral colony was not always smaller than the distance between two grid points (see van der Plas and Tobi 1965).

Taxonomic richness and diversity were evaluated for each quadrat, and the arithmetic means plus $95 \%$ 


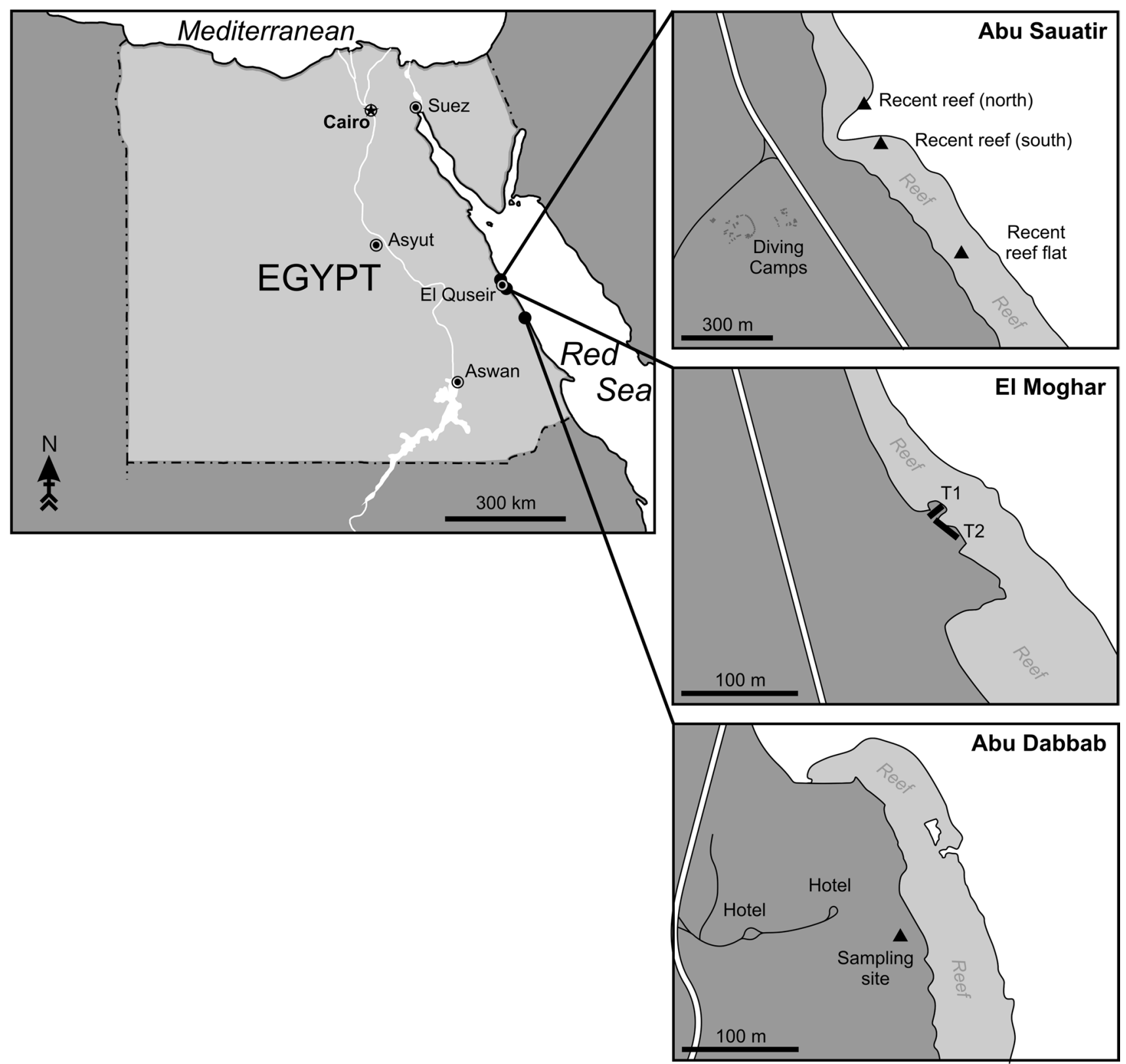

Fig. 1 Study sites of the modern reef at Abu Sauatir and the fossil reef terraces at El Mohgar and Abu Dabbab, Egypt

confidence intervals were calculated for each habitat. Richness was measured as the total number of genera and diversity was measured with the Shannon-Wiener index (Shannon 1948). The Margalef index (Margalef 1958) and Simpson index (Simpson 1949) showed similar trends as the Shannon-Wiener index and are therefore not shown here. The Mann-Whitney $U$ test (Mann and Whitney 1947) was used to compare the northern and the southern transects of the reef edge and the slope.

We evaluated the difference between all modern reef habitats and the fossil reefs using one-way analysis of similarity (ANOSIM; Clarke and Warwick 1994). Pairwise comparisons yielding $R$ values above 0.75 (well separated), above 0.5 (overlap, but clearly separated), above 0.25 (stronger overlap, poorly separated) or under 0.25 (negligible separation) display the degree of separation between habitats (Clarke and Gorley 2006). Non-metric multidimensional scaling (MDS; Kruskal 1964) was used to visualize the differences among all habitats. The Bray-Curtis similarity index (Bray and Curtis 1957) was chosen as distance measure. The distances between two points represent the ranks of dissimilarity (Clarke and Gorley 2006). Similarity percentages (SIMPER; Clarke and Warwick 1994) were calculated to evaluate which taxa primarily contributed to 

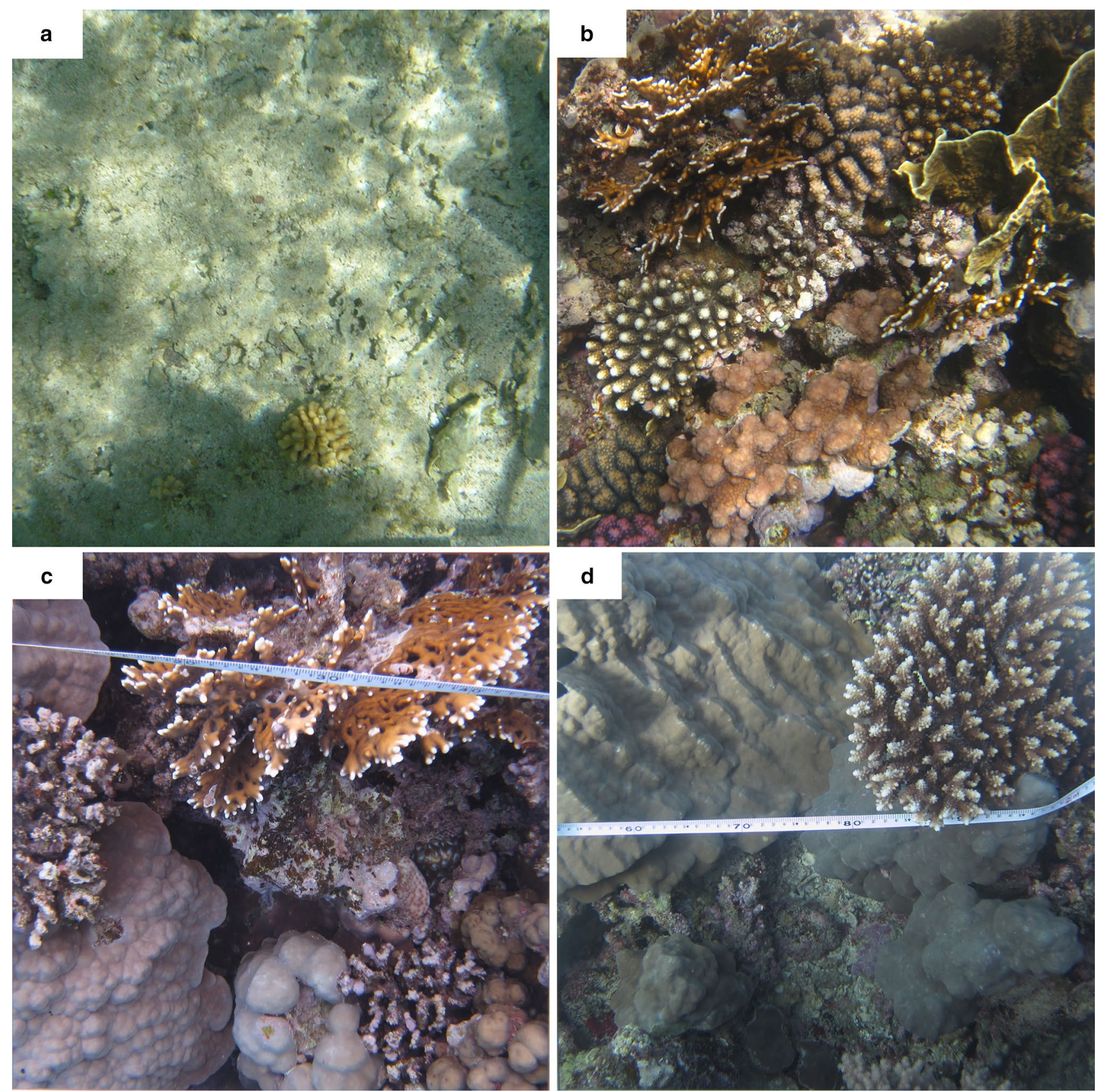

Fig. 2 Modern reef habitats: transect pictures of the a reef flat with Stylophora; b reef edge with Acropora, Millepora, Pocillopora, and others; c reef slope in 5-m depth with Porites, Millepora, and others; and $\mathbf{d}$ reef slope in 10-m depth with Porites and Acropora, and others

dissimilarities between the habitats. These analyses were done using the software package PAST (Hammer et al. 2001) and PRIMER 6 (Clarke and Gorley 2006).

Scleractinians and Millepora were identified to genus level because species identification based on photographs alone was not consistently possible. Genus data, however, are considered sufficient for the purpose of this study because, based on an extensive data set, Pandolfi (2001) concluded that analyses of Quaternary coral communities are robust to taxonomic scale between species and genus level. Sessile mollusks were identified to genus level but later pooled due to low numbers. Other biota categories included Porifera, octocorals and non-coralline algae. Coral rubble, dead corals, sand and coralline algae could not be consistently distinguished and were therefore combined for the analyses (category "coral rubble/coralline red algae").

In addition, data of the northern and southern reef edge as well as reef slope transects were pooled, as there were no 

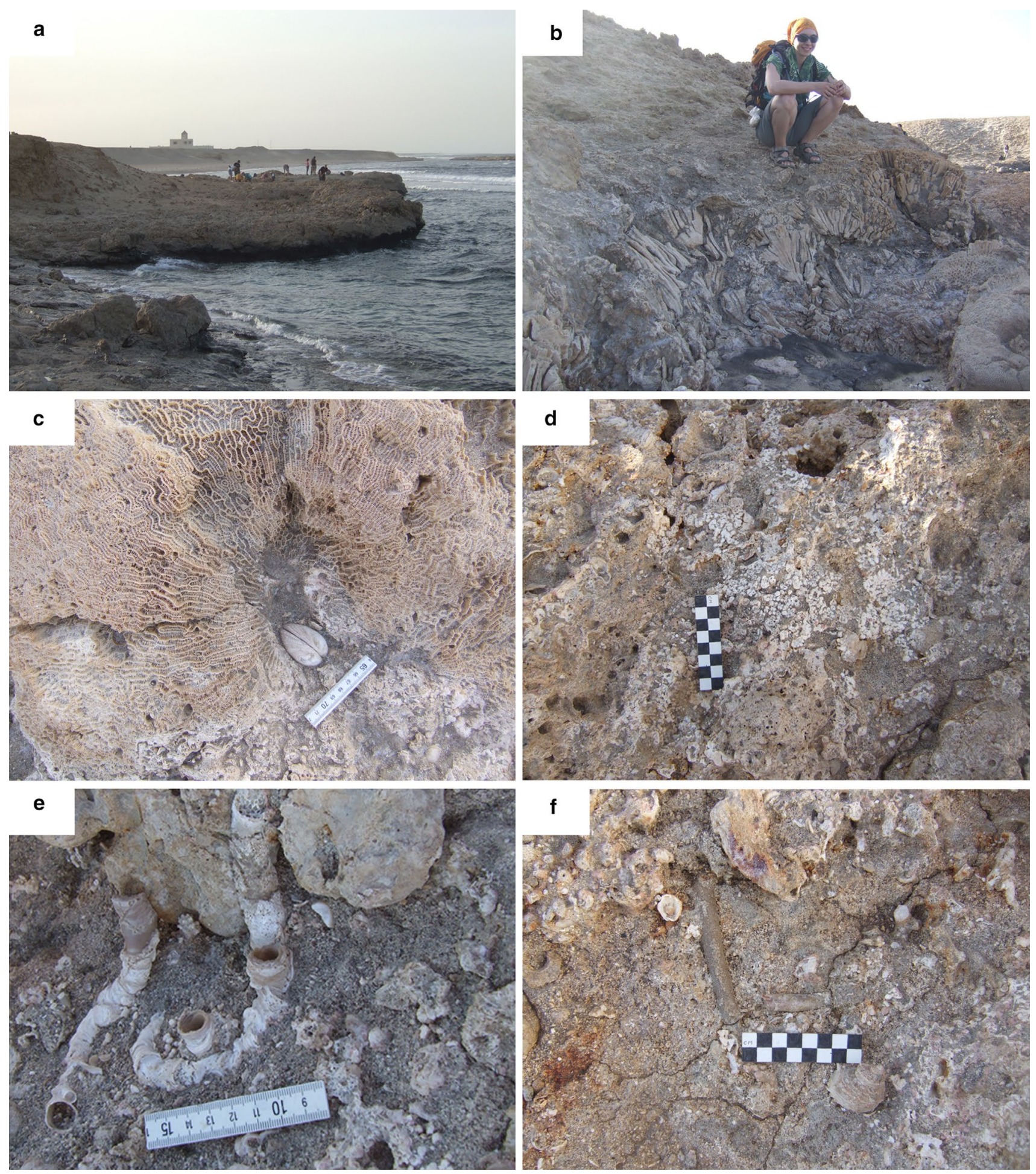

Fig. 3 Fossil reef terraces: a the studied terraces at El Mohgar, b framestone of Lobophyllia patch reef at Abu Dabbab, $\mathbf{c}$ framestone with coral Leptoria and venerid bivalve Periglypta at Abu Dabbab, d bindstone with coralline red algae at El Mohgar, e bindstone with the

vermetid gastropod Dendropoma maxima and coralline red algae at El Mohgar, f rudstone with spines of Heterocentrotus mamilatus and gastropod Turbo radiatus at El Mohgar 

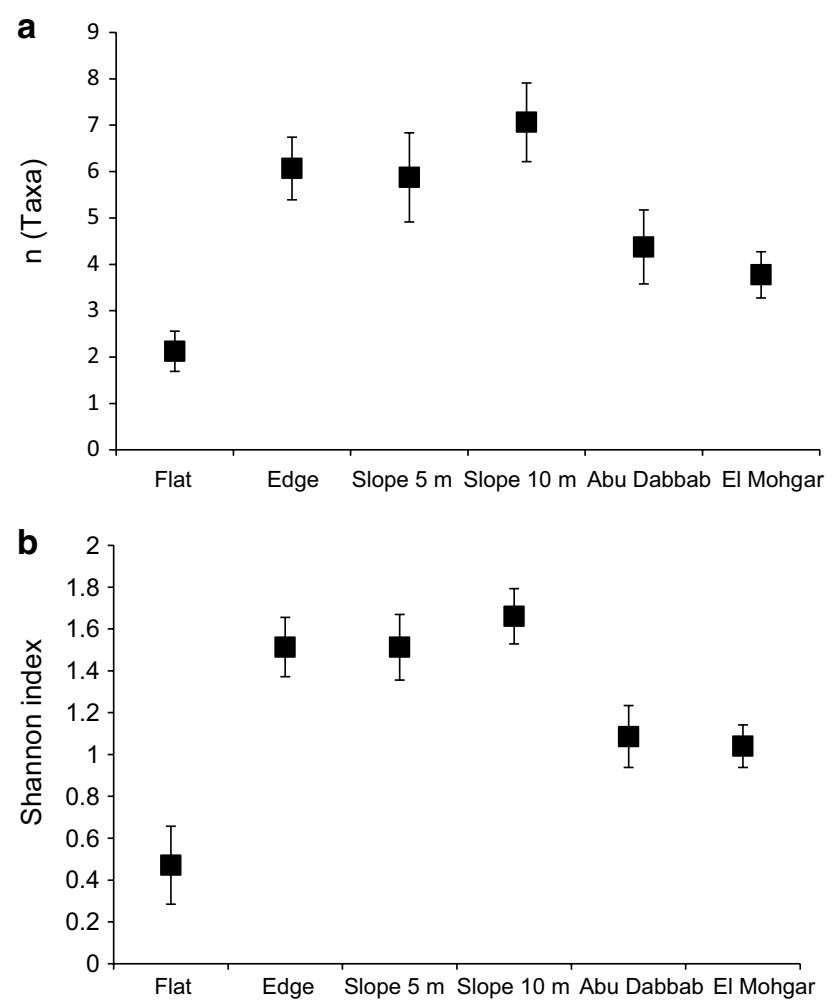

Fig. 4 a Taxonomic richness measured as average number of genera and b Shannon-Wiener index for each habitat. Error bars represent $95 \%$ confidence intervals

significant differences between the two sites (Mann-Whitney test; $U=401.5 ; p=0.3812, U=447 ; p=0.9667$, respectively). Three samples (one modern, two fossil) were dominated by single taxa and excluded from statistical analysis because they were outliers in all statistical analyses.

\section{Results}

\section{Abundance and diversity of the modern reef}

Taxonomic richness and diversity increase from the reef flat towards the reef slope, with a small drop on the reef slope at 5-m depth (Fig. 4). Stylophora is the only coral genus found on the reef flat; the reef edge holds 10 , the reef slope at 5-m depth 16, and the slope at 10-m depth 17 genera of stony corals (Table 1). Acropora and Pocillopora are the most abundant hexacorals on the reef edge; Pocillopora is also dominant at 5-m depth (Table 1; Figs. 5, 6). Porites is the dominant genus at $10-\mathrm{m}$ depth, followed by Acropora (Table 1; Figs. 5, 6).

\section{Abundance and diversity of the fossil reefs}

The fossil reefs in El Mohgar and Abu Dabbab have similar compositions (Table 1; Fig. 7): Coral rubble, sand and coralline algae account for 67 and $73 \%$, respectively, and Porites is the most abundant coral genus. However, Dipsastraea makes up $13 \%$ of total coverage in El Mohgar, but is rare (3\%) in Abu Dabbab). Leptoria is exclusively found in Abu Dabbab. Overall, nine taxa were found in Abu Dabbab and El Mohgar, respectively (Table 1).

Species richness and diversity are lower at the fossil sites than on the modern reef edge and slope, but considerably higher than on the reef flat. The Shannon-Wiener index is marginally lower in El Mohgar $(H=1.040)$ than in Abu Dabbab ( $H=1.086$; Fig. 4).

\section{Modern reef habitats in comparison}

Most modern reef habitats and the two fossil sites are well separated from each other. Among the modern habitats, however, the reef slope at 5-m water depth differs only slightly from the reef edge and the slope at $10-\mathrm{m}$ depth (Table 2). The reef flat is the most distinct modern reef habitat, as is also shown by ordination (Fig. 8). The other three modern reef habitats overlap partially.

Coral rubble/coralline algae is the most important category in all habitats. On the reef flat, this category contributed almost $90 \%$ to average similarity (see Electronic Supplementary Material, S1). On the reef edge, coral rubble/ coralline algae (64\%) and Pocillopora $(16.6 \%)$ are important. The reef slope in 5-m depth is similar to the reef edge: four groups contribute $94 \%$ to average similarity; coral rubble/coralline algae (53 \%) is followed by Pocillopora (24\%) and Millepora (13\%). In 10-m depth, five groups contribute $93 \%$; most important are coral rubble/coralline algae (56\%), Acropora (15\%), and Porites (15\%).

Coral rubble/coralline algae is also the largest contributor to the average dissimilarity between the reef flat and all other modern reef habitats (see Electronic Supplementary Material, S2). The reef flat is best distinguished from the reef edge and reef slope at 5-m water depth by Pocillopora, and from the reef slope at 10-m depth by Porites, Acropora, and coral rubble/coralline algae. Millepora, Pocillopora, and coral rubble discriminate the best between the reef edge and the reef slope in $5 \mathrm{~m}$, and Porites, Acropora, and Pocillopora between the reef edge and the reef slope at $10 \mathrm{~m}$. The two reef slope habitats are best distinguished by Pocillopora, (highly abundant at 5-m depth), followed by Millepora, Porites, and Acropora. 
Table 1 Percentage cover of all taxa and taxonomic groups found in the modern and fossil reefs

\begin{tabular}{|c|c|c|c|c|c|c|}
\hline & Reef flat & Reef edge & Reef slope $5 \mathrm{~m}$ & Reef slope $10 \mathrm{~m}$ & El Mohgar & Abu Dabbab \\
\hline $\mathrm{CR} / \mathrm{CA}$ & 85 & 56 & 51 & 56 & 67 & 73 \\
\hline Stylophora & $<1$ & 2 & $<1$ & 1 & 1 & \\
\hline Pocillopora & & 9 & 18 & 2 & & $<1$ \\
\hline Porites & & $<1$ & 5 & 15 & 16 & \\
\hline Montipora & & $<1$ & 2 & 3 & & \\
\hline Acropora & & 7 & 3 & 10 & $<1$ & $<1$ \\
\hline Millepora & & 9 & 15 & 2 & $<1$ & $<1$ \\
\hline Goniastrea & & 4 & $<1$ & 1 & & \\
\hline Octocorals & & & 3 & 6 & & \\
\hline Sessile molluscs & $<1$ & $<1$ & & & $<1$ & $<1$ \\
\hline Non-coralline algae & 14 & 7 & 1 & 1 & & \\
\hline Porifera & $<1$ & $<1$ & 1 & $<1$ & & \\
\hline Dipsastraea & & 1 & $<1$ & 1 & 13 & 3 \\
\hline Favites & & 1 & $<1$ & $<1$ & 1 & $<1$ \\
\hline Leptoria & & 1 & $<1$ & & & 4 \\
\hline Hydnophora & & $<1$ & $<1$ & $<1$ & & \\
\hline Coscinaraea & & & $<1$ & & & \\
\hline Tubastrea & & & & $<1$ & & \\
\hline Astreopora & & & & 1 & & \\
\hline Psammocora & & & & $<1$ & & \\
\hline Pavona & & & & 1 & & \\
\hline Leptoseris & & & 1 & $<1$ & & \\
\hline Cyphastrea & & & & $<1$ & & \\
\hline Pachyseris & & & & $<1$ & & \\
\hline Gardineroseris & & & $<1$ & 1 & & \\
\hline Echinopora & & $<1$ & $<1$ & & & \\
\hline Turbinaria & & & $<1$ & & & \\
\hline Siderastrea & & & $<1$ & & & \\
\hline Galaxea & & & & & 1 & 1 \\
\hline Lobophyllia & & & & & $<1$ & $<1$ \\
\hline Total $(n)$ & 5 & 16 & 21 & 22 & 10 & 10 \\
\hline
\end{tabular}

CR/CA Coral rubble/Coralline algae

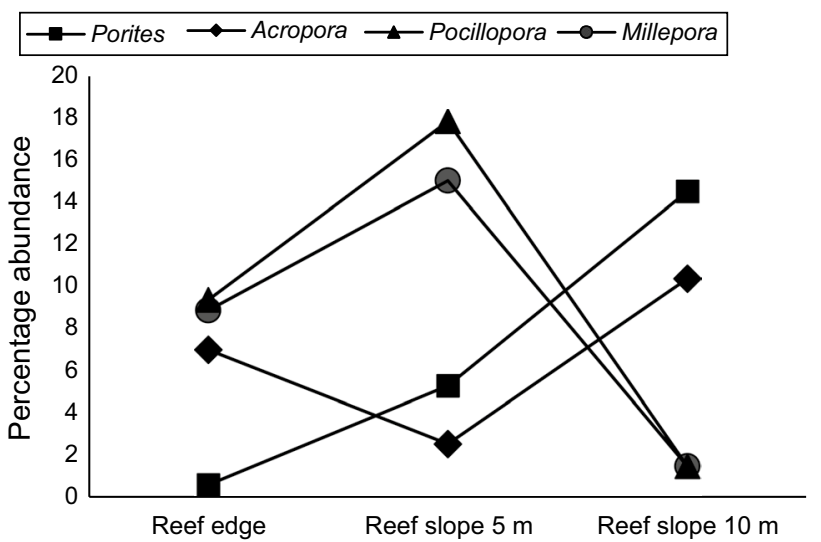

Fig. 5 Percentage per habitat of most abundant corals in the modern reef (excluding reef flat as none of these genera can be found there)

\section{Modern versus fossil reefs}

Results of ANOSIM indicate a very high similarity between the two fossil sites, however, both are well separated from all modern habitats (Table 2). The reef slope at 10-m depth is the most similar to the fossil sites $(R$ values $<0.6)$ of all habitats in the Recent reef. These results are reflected in the MDS (Fig. 8), where the reef slope at $10 \mathrm{~m}$ and the two fossil sites plot relatively close to each other.

Coral rubble/coralline algae and Porites contribute more than $90 \%$ to the average similarity in Abu Dabbab and El Mohgar (see Electronic Supplementary Material, S1). Fifteen and fourteen taxa contribute over $90 \%$ to the average dissimilarity between Abu Dabbab/El Mohgar and the reef slope at 10-m depth, respectively (see Electronic Supplementary Material, S2). Acropora, coral rubble/coralline 
a

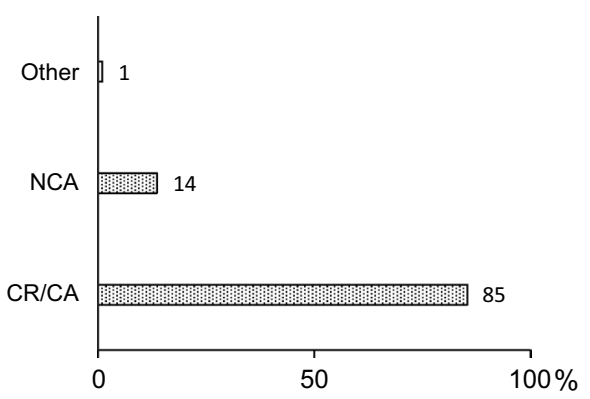

C

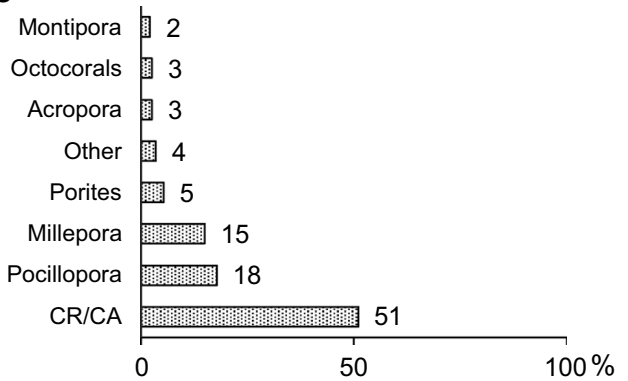

b

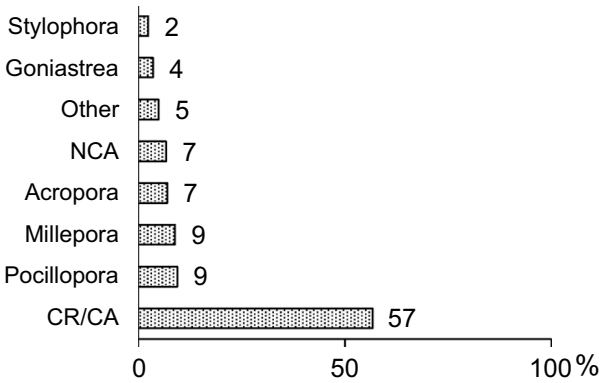

d

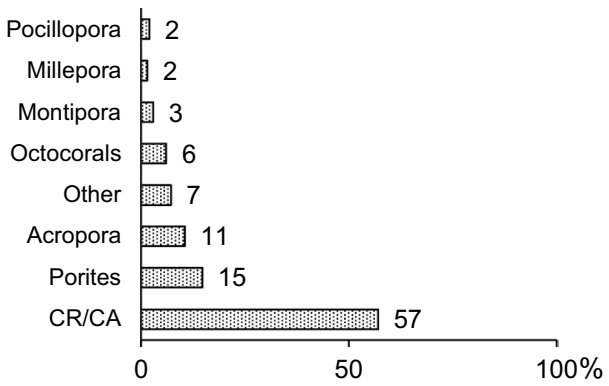

Fig. 6 Coverage of the four studied habitats of the Recent reef: a reef flat, b reef edge, $\mathbf{c}$ reef slope $5 \mathrm{~m}$, $\mathbf{d}$ reef slope $10 \mathrm{~m}$. $C R / C A$ Coral rubble/Coralline algae, $N C A$ non-coralline algae. All taxa accounting

for less than $2 \%$ were pooled as "other". Standard errors of sample proportion are too small $(0.3-1.2 \%)$ to be presented here
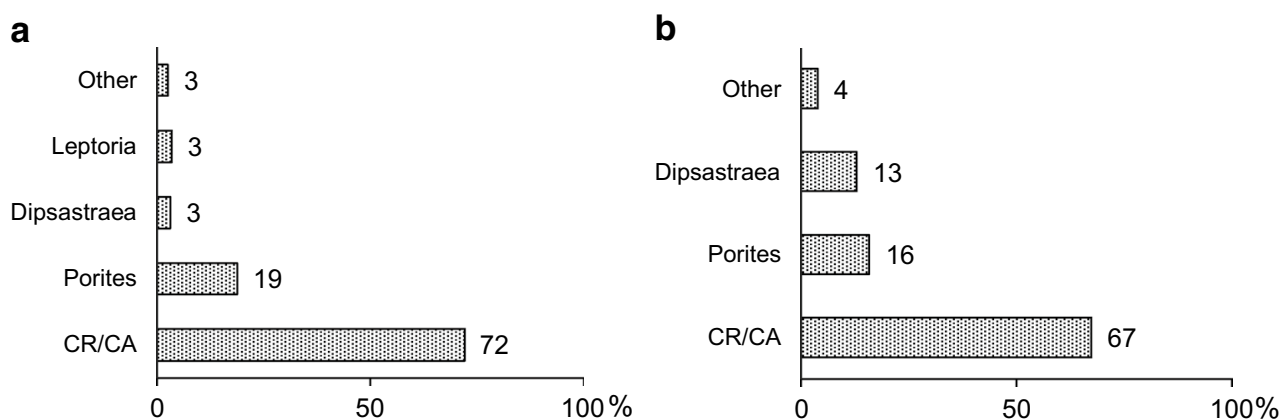

Fig. 7 Coverage of the two fossil reefs at a Abu Dabbab and $\mathbf{b}$ El Mohgar. $C R / C A$ Coral rubble/Coralline algae. All taxa accounting for less than $2 \%$ were pooled as "other". Standard errors of sample proportion are too small $(0.4-1 \%)$ to be presented here

Table $2 R$ values (bottom left) and Bonferroni-corrected $p$ values (top right) of the pairwise comparisons between the different habitats of the modern reef and the fossil reefs in Abu Dabbab and El Mohgar with one-way ANOSIM (distance measure: Bray-Curtis similarity index)

\begin{tabular}{lllllll}
\hline & Reef edge & Reef flat & Slope 5 m & Slope 10 m & Abu Dabbab & El Mohgar \\
\hline Reef edge & & 0.0015 & 0.0030 & 0.0015 & 0.0015 & 0.0015 \\
Reef flat & 0.5129 & & 0.0015 & 0.0015 & 0.0015 & 0.0015 \\
Slope 5 m & 0.3067 & 0.9515 & & 0.0015 & 0.0015 & 0.0015 \\
Slope 10 m & 0.4515 & 0.8006 & 0.4832 & & 0.0015 & 0.0015 \\
Abu Dabbab & 0.6814 & 0.6859 & 0.8361 & 0.5175 & & 0.9975 \\
El Mohgar & 0.7795 & 0.6903 & 0.8588 & 0.6020 & 0.07889 & \\
\hline
\end{tabular}

$R$ overall $=0.6065 ; p=0.0001$ 


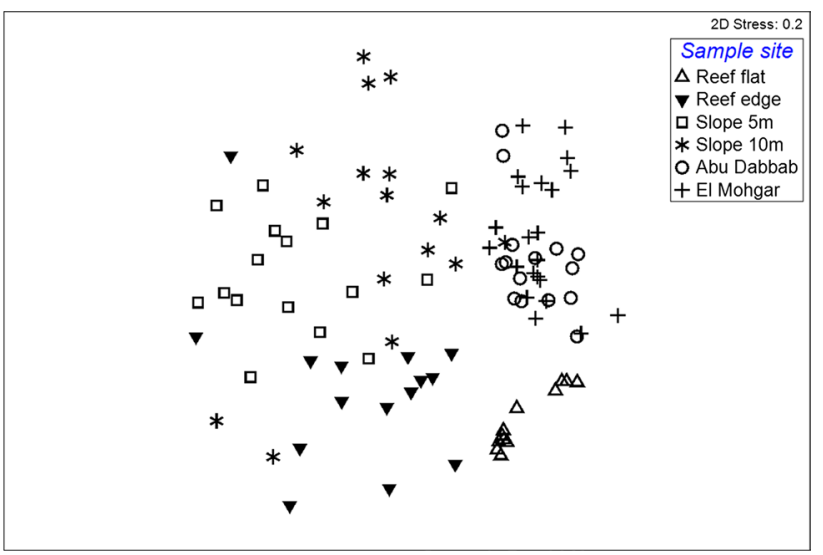

Fig. 8 MDS plot of all reef habitats (distance measure: Bray-Curtis similarity index)

algae, and Porites (with decreasing contribution) are the three most discriminating taxa between the reef slope at $10 \mathrm{~m}$ and the Pleistocene assemblage of Abu Dabbab, whereas for El Mohgar these are Acropora, Porites, Dipsastraea, and coral rubble/coralline algae.

\section{Discussion}

Although we found a significant difference between all modern predefined reef habitats, the degree of separation varies considerably. The reef edge and the reef slope at 5-m depth are the least separated, probably because the difference in water depth is small. Including images from the most wave-exposed part, on the actual reef crest, would probably have led to slightly different results, but this was not possible during our fieldwork.

The Abu Sauatir reef shows the assemblages typical for wind-exposed settings with a steep relief as described by Riegl and Velimirov (1994) from the northern Red Sea. A relatively high abundance of Millepora on the reef edge and the upper reef slope has also been documented for other localities in the northern Red Sea (e.g., Loya and Slobodkin 1971; Riegl and Velimirov 1994) and indicates the exposition to currents (Riegl and Piller 1997).

A comparison of coral coverage data of the modern reef suggests similarities in mean values and trends with water depth with nearby localities: At Abu Sauatir (this paper), coral cover is the highest at 10-m depth, nearly as high at $5 \mathrm{~m}$ and at the reef edge, and clearly the lowest on the reef flat. The drop in diversity from reef edge to reef slope at 5-m depth can be attributed to the dominance of Millepora and Pocillopora at $5 \mathrm{~m}$. The sites examined by Riegl and Velimirov (1994) at Hurghada had similarly high coral coverage, with values ranging from 36 to $82 \%$ (plus considerable soft coral cover at some of their sites). Stony coral coverage was not significantly different between the sheltered, semi-exposed, and exposed sites, and the sheltered group of reefs included both the highest and lowest coral cover observed by Riegl and Velimirov (1994). Riegl and Piller (2000) compared live coral coverage in different reef habitats at Safaga in the northern Red Sea and also found uniformly high coverage ranging from 43 to $59 \%$ in reef crest, reef edge, reef slope and slope base habitats of exposed and semi-exposed sites. Sheltered localities, however, had strongly variable coverage ranging from 24 to $26 \%$ on the reef crest and slope base sites, respectively, to $68 \%$ on the reef edge and even $85 \%$ on the slope and in and low-relief areas. Alter (2004) surveyed the species composition, zonation and diversity patterns of reef-building coral communities in the Gulf of Aqaba. In contrast to our study, he found coral cover to be the highest $(36.5 \%)$ on the upper reef slope at 0.5-3 m-depth, and it decreased with increasing depth to $20 \%(3-7 \mathrm{~m})$ and $13.4 \%$ $(8-12 \mathrm{~m})$. With the exception of the reef flat $(11.1 \%)$, those coverage values are lower than on the modern reef in Abu Sauatir. Loya (1972) reported a higher mean coverage from Eilat, but the overall trend of decreasing coverage from the reef edge to the reef slope was the same.

The quantitative composition of the fossil assemblages at the two sites was compared to the modern habitats in order to estimate their depositional water depth. At large spatial scale by-occurrence subsampling leads to interpretable results (Kiessling et al. 2012). However, we did not subsample our data due to low numbers of quadrats (16 per modern reef habitat, 39 in the fossil reefs) and genera (only nine genera of stony corals were found in the fossil reefs). The fossil reefs are most similar to-but still significantly different from-the modern reef slope at 10-m water depth. There are two possible interpretations: (1) the fossil terraces belong to quiet-water conditions of a lagoon, which would also show a similar species composition, or (2) the fossil terraces belong to a reef slope at about 10-m water depth and differences to the modern reef at this depth reflect taphonomic bias, and/or natural temporal and spatial variability of coral communities.

Porites is among the dominant taxa at both fossil localities. Modern communities dominated by massive Porites are either taken as an indicator for shallow reef environments with moderate wave energy such as back-reef margins or lagoons (Riegl and Velimorov 1994; Veron 2000; Montaggioni 2005; Gischler et al. 2008; Hongo and Kayanne 2011) or may indicate low-energy environments at depths of 10-15 m (Done 1982; Riegl and Velimorov 1994; Riegl and Piller 1999; Grossman and Fletcher 2004; Montaggioni 2005). At our modern study site, massive Porites increased with water depth, being the dominant genus in $10-\mathrm{m}$ depth. Back-reef zones are absent in the modern reef we studied and could thus not be used for comparison to 
the fossil reefs. However, the mean sea level was higher during the Eemian, and back-reef deposits are present in MIS 5e reefs at Quseir el Qadim (Plaziat et al. 1998; Taviani 1998a). It is therefore possible that the Porites- and merulinid-dominated coral communities of the fossil reef terraces were once situated in a lagoonal back-reef habitat. The idea of tectonic uplift in this area has been rejected in numerous publications (e.g., Hoang and Taviani 1991; Bosworth and Taviani 1996; Plaziat et al. 1998, 2008), which supports the interpretation of the fossil terraces as backreefs rather than reef slopes. However, in a study that takes glacio-hydro-isostatic processes into account, Lambeck et al. (2011) conclude that long-term tectonic uplift along the northern and central sides of the Red Sea is more likely than tectonic stability. The uplift rate for Quseir el Qadim is stated as $0.057 \mathrm{~mm}$ per year and the observed Last Interglacial sea level as $7 \mathrm{~m}$ higher than today (Plaziat et al. 2008; Lambeck et al. 2011). Thus, the MIS 5e fossil reef terraces that are situated 3-5 $\mathrm{m}$ above sea level today could have been reef slopes at around 10-m depth or deeper.

Arborescent corals and most notably Milleporidae, which are abundant in certain zones of the studied modern reefs, were absent or underrepresented in the fossil reefs studied here. This difference could result from the fossil sites representing a lagoonal habitat that is not present in the modern reef we studied. Another possible reason for this discrepancy, however, is taphonomic bias because life and death assemblages of coral reefs typically differ significantly (Greenstein and Pandolfi 1997; Pandolfi and Greenstein 1997a, b; Edinger et al. 2001). These differences are mostly attributed to growth form biases, typically towards arborescent growth forms in death assemblages, but are also influenced by the environment (Greenstein and Pandolfi 2003).

Finally, the differences between the fossil sites studied and any of our studied modern habitats could reflect the natural spatial and temporal variability observed in the modern Red Sea. The modern reef was 25 and $110 \mathrm{~km}$ away from the fossil reef terraces in El Mohgar and Abu Dabbab, respectively. Thus, differences between modern and fossil reefs could be partly caused by such local effects. In the northern Red Sea, however, differences between coral communities at different localities and water depths are mostly due to hydrodynamic exposure, with massive Porites always being characteristic for sheltered conditions (Riegl and Velimirov 1994). Moreover, coral coverage may differ widely in the northern Red Sea as outlined above, but coral zonation is very conservative (e.g., Riegl and Velimirov 1994; Riegl and Piller 1997). In a survey that spanned 20 years, a trend towards increasing community homogenization and decreasing average size of coral colonies in the Red Sea was found and related to the impact of climate change (Riegl et al. 2012). These trends, however, are subtle compared to the strong differences between the modern and fossil reefs in our study. We are therefore confident that these differences reflect either different habitats or taphonomic bias and not natural spatial or temporal variability of coral communities in the northern Red Sea.

\section{Conclusions}

This is one of the few attempts to evaluate the depositional water depth of late Pleistocene reef terraces (here tentatively assigned to MIS 5e) at the Red Sea by quantitative analysis of coral coverage and taxonomic composition (see also Mewis and Kiessling 2013). The studied modern reef at Abu Sauatir shows the assemblages of wind-exposed settings with a steep relief that are typical for the northern Red Sea. Live coral coverage is similar to values reported from other localities in the region but differs strongly from those reported from the Gulf of Aqaba. Except for the reef flat, the fossil reefs studied at Abu Dabbab and El Mohgar were less diverse and less rich in taxa than the modern reef habitats. Considering tectonic activity and sea-level change, the fossil reefs must have been situated at 10-m depth or deeper. This is corroborated by statistical analysis: While the fossil reef terraces are significantly different from all modern habitats, they are most similar to the modern reef slope at $10-\mathrm{m}$ depth. We attribute differences to the modern reef slope mainly to selective loss of arborescent and branching corals during fossilization and mixing of life and death assemblages in the fossil reef. However, should the hypothesis of tectonic stability be correct, a second way to interpret the data is that the fossil reefs belonged to a back-reef lagoon, which is absent in the modern reef.

Acknowledgments Mathias Bichler supplied the GPS data of all study sites. Lukas Pressler, Patrick Jambura, Bettina Glasl, and Judith Ullmann provided the transect photos of the reef slope in 10-m depth. We especially thank Kristof Veitschegger, Wolfgang Eder, and David Gröbner for their help in identifying and counting taxa. We are grateful to Karl Kleemann for aiding in coral identification and to Michael Stachowitsch for comments on the manuscript. The careful and stimulating reviews of Marco Taviani, anonymous colleagues and editor Wolfgang Kiessling greatly improved the manuscript.

Open Access This article is distributed under the terms of the Creative Commons Attribution 4.0 International License (http://creativecommons.org/licenses/by/4.0/), which permits unrestricted use, distribution, and reproduction in any medium, provided you give appropriate credit to the original author(s) and the source, provide a link to the Creative Commons license, and indicate if changes were made. 


\section{References}

Alter C (2004) Diversity, community structure and zonation of zooxanthellate, hermatypic corals of the reef complex at The Islands dive site, Dahab, in the Gulf of Aqaba. Unpublished M.Sc. thesis, Universität Heidelberg

Andres W, Radtke U, Mangini A (1988) Quartäre Strandterrassen an der Küste des Gebel Zeit (Golf von Suez/Ägypten). Erdkunde 42:7-16

Bohnsack JA (1979) Photographic quantitative sampling of hard-bottom benthic communities. B Mar Sci 29(2):242-252

Bosworth W, Taviani M (1996) Late Quaternary reorientation of stress field and extension direction in the southern Gulf of Suez, Egypt: evidence from uplifted coral terraces, mesoscopic fault arrays, and borehole breakouts. Tectonics 15:791-802

Bray JR, Curtis JT (1957) An ordination of the upland forest communities of Southern Wisconsin. Ecol Monog 27:325-349

Clarke KR, Gorley RN (2006) Primer v6: user manual/tutorial. Primer-E Ltd., Plymouth

Clarke KR, Warwick RM (1994) Change in marine communities: an approach to statistical analysis and interpretation. Primer-E Ltd., Plymouth

Done T (1982) Patterns in the distribution of coral communities across the central Great Barrier Reef. Coral Reefs 1:95-107

Dullo W-C (1984) Progressive diagenetic sequence of aragonite structures: Pleistocene coral reefs and their modern counterparts on the eastern Red Sea coast, Saudi Arabia. Palaeontogr Am $54: 254-260$

Dullo W-C (1986) Variation in diagenetic sequences: an example from Pleistocene coral reefs, Red Sea, Saudi Arabia. In: Schröder JH, Purser BH (eds) Reef diagenesis. Springer, Berlin, pp 77-90

Dullo W-C (1990) Facies, fossil record, and age of Pleistocene reefs from the Red Sea (Saudi Arabia). Facies 22:1-46

Edinger EN, Pandolfi JM, Kelley RA (2001) Community structure of Quaternary coral reefs compared with Recent life and death assemblages. Paleobiology 27:669-694

Edinger EN, Burr GS, Pandolfi JM, Ortiz JC (2007) Age accuracy and resolution of Quaternary corals used as proxies for sea level. Earth Planet Sc Lett 253:37-49

El Moursi M, Hoang CT, Fayoumy IFE, Hegab O, Faure H (1994) Pleistocene evolution of the Red Sea coastal plain, Egypt: evidence from uranium-series dating of emerged reef terraces. Quat Sci Rev 1:345-359

Gischler E, Hudson JH, Pisera A (2008) Late Quaternary reef growth and sea level in the Maldives (Indian Ocean). Mar Geol 250:104-113

Greenstein BJ, Pandolfi JM (1997) Preservation of community structure in modern reef coral life and death assemblages of the Florida Keys: implications for the Quaternary fossil record of coral reefs. B Mar Sci 61:431-452

Greenstein BJ, Pandolfi JM (2003) Taphonomic alteration of reef corals: effects of reef environment and coral growth form II: the Florida Keys. Palaios 18:495-509

Grossman EE, Fletcher CH (2004) Holocene reef development where wave energy reduces accommodation space Kailua Bay windward Oahu Hawaii USA. J Sediment Res 741:49-63

Gvirtzman G (1994) Fluctuations of sea level during the past 400,000 years: the record of Sinai, Egypt (Northern Red Sea). Coral Reefs 13:203-214

Gvirtzman G, Friedman GM (1977) Sequence of progressive diagenesis in coral reefs. Stud Geol 4:357-380

Hammer Ø, Harper DAT, Ryan PD (2001) PAST: paleontological statistics software package for education and data analysis. Palaeontol Electron 4(1). http://palaeo-electronica.org/2001_1/past/ issue1_01.htm. Accessed Oct 2012
Hoang CT, Taviani M (1991) Stratigraphic and tectonic implications of uranium-series-dated coral reefs from uplifted Red Sea Islands. Quat Res 35:264-273

Hongo C, Kayanne H (2011) Key species of hermatypic coral for reef formation in the Northwest Pacific during Holocene sea-level change. Mar Geol 279:162-177

Kiessling W, Simpson C, Beck B, Mewis H, Pandolfi JM (2012) Equatorial decline of reef corals during the last Pleistocene interglacial. P Natl Acad Sci USA 109(52):21378-21383

Kruskal JB (1964) Multidimensional scaling by optimizing goodness of fit to a nonmetric hypothesis. Psychometrika 29:1-27

Lambeck K, Purcell A, Flemming NC, Vita-Finzi C, Alsharekh AM, Bailey GN (2011) Sea level and shoreline reconstructions for the Red Sea: isostatic and tectonic considerations and implications for hominin migration out of Africa. Quat Sci Rev 30:3542-3547

Legendre P, Legendre L (1998) Numerical ecology. Elsevier, Amsterdam

Lough JM, Barnes DJ (1997) Several centuries of variation in skeletal extension, density and calcification in massive Porites colonies from the Great Barrier Reef: a proxy for seawater temperature and a background of variability against which to identify unnatural change. J Exp Mar Biol Ecol 211:29-67

Loya Y (1972) Community structure and species diversity of hermatypic corals at Eilat, Red Sea. Mar Biol 13:100-123

Loya Y, Slobodkin LB (1971) The coral reefs of Eilat (Gulf of Eilat, Red Sea). Symp Zool Soc Lond 28:117-139

Mann HB, Whitney DR (1947) On a test of whether one of two random variables is stochastically larger than the other. Ann Math Stat 18:50-60

Margalef R (1958) Information theory in ecology. General Syst Yearbook Soc Gen Syst Res 3:36-71

Mewis H, Kiessling W (2013) Environmentally controlled succession in a late Pleistocene coral reef (Sinai, Egypt). Coral Reefs 32:49-58

Montaggioni LF (2005) History of Indo-Pacific coral reef systems since the last glaciation: development patterns and controlling factors. Earth Sci Rev 71:1-75

Pandolfi JM (2001) Numerical and taxonomic scale of analysis in paleoecological data sets: examples from neo-tropical Pleistocene reef coral communities. J Paleontol 75:546-564

Pandolfi JM, Greenstein BJ (1997a) Preservation of community structure in death assemblages of deep-water Caribbean reef corals. Limnol Oceanogr 42:1505-1516

Pandolfi JM, Greenstein BJ (1997b) Taphonomic alteration of reef corals: effects of reef environment and coral growth form I: the Great Barrier Reef. Palaios 12:27-42

Pandolfi JM, Greenstein BJ (2007) Using the past to understand the future: palaeoecology of coral reefs. In: Johnson JE, Marshall PA (eds) Climate change and the Great Barrier Reef: a vulnerability assessment. Great Barrier Reef Marine Park Authority and the Australian Greenhouse Office, Townsville, pp 717-744

Parker JH, Gischler E, Eisenhauer A (2012) Biodiversity of Foraminifera from Late Pleistocene to Holocene coral reefs, South Sinai, Egypt. Mar Micropaleontol 86-87:59-75

Pilliod DS, Arkle RS (2013) Performance of quantitative vegetation sampling methods across gradients of cover in Great Basin plant communities. Rangeland Ecol Manag 66:634-647

Plaziat J-C, Baltzer F, Choukri A, Conchon O, Freytet P, OrszagSperber F, Raguideau A, Reyss J-L (1998) Quaternary marine and continental sedimentation in the northern Red Sea and Gulf of Suez (Egyptian coast): influences of rift tectonics, climatic changes and sea-level fluctuations. In: Purser BH, Bosence DWJ (eds) Sedimentation and tectonics of Rift Basins: Red Sea-Gulf of Aden. Chapman \& Hall, London, pp 537-573 
Plaziat J-C, Reyss JL, Choukri A, Cazala C (2008) Diagenetic rejuvenation of raised coral reefs and precision of dating. The contribution of the Red Sea reefs to the question of reliability of the uranium-series datings of Middle to Late Pleistocene key reefterraces of the world. Carnets de Géologie/Notebooks on Geology, Article 2008/04, (CG2008_A04)

Riegl B, Piller WE (1997) Distribution and environmental control of coral associations in northern Safaga Bay, Red Sea, Egypt. Facies 36:141-162

Riegl B, Piller WE (1999) Coral frameworks revisited-reefs and coral carpets in the Northern Red Sea. Coral Reefs 18:241-253

Riegl B, Piller WE (2000) Mapping of benthic habitats in northern Safaga Bay (Red Sea, Egypt): a tool for proactive management. Aquatic Cons 10:127-140

Riegl B, Velimirov B (1994) The structure of coral communities at Hurghada in the Northern Red Sea. Mar Ecol 15:213-231

Riegl BM, Bruckner AW, Rowlands GP, Purkis SJ, Renaud P (2012) Red Sea coral reef trajectories over 2 decades suggest increasing community homogenization and decline in coral size. PLoS One. doi:10.1371/journal.pone.0038396

Shannon CE (1948) A mathematical theory of communication. Bell Syst Tech J 27:379-423/623-656
Simpson EH (1949) Measurement of diversity. Nature 163:688

Strasser A, Strohmenger C (1997) Early diagenesis in Pleistocene coral reefs, southern Sinai, Egypt: response to tectonics, sealevel and climate. Sedimentology 44:537-558

Taviani M (1998a) Post-Miocene reef faunas of the Red Sea: glacioeustatic controls. In: Purser BH, Bosence DWJ (eds) Sedimentation and Tectonics of Rift Basins: Red Sea-Gulf of Aden. Chapman \& Hall, London, pp 574-582

Taviani M (1998b) Stable tropics not so stable: climatically driven extinctions of reef-associated molluscan assemblages (Red Sea and western Indian Ocean: last interglaciation to present). Spec Publ int Ass Sedimentol 25:69-76

van der Plas L, Tobi AC (1965) A chart for judging the reliability of point counting results. Am J Sci 263:87-90

Veeh HH, Giegengack R (1970) Uranium-series ages of corals from the Red Sea. Nature 226:155-156

Veron JEN (2000) Corals of the world, vol. 1. 2. 3. Australian Institute of Marine Science, Townsville

Walther J (1888) Die Korallenriffe der Sinaihalbinsel. Geologische und biologische Beobachtungen. In: Abhandlungen der Mathematisch-Physischen Klasse der Königlich-Sächsischen Gesellschaft der Wissenschaften. S. Hirzel Verlag, Leipzig, pp 440-505 